\title{
Development and Field Evaluation of a Model to Estimate the Maturity of Pseudothecia of Pleospora allii on Pear
}

\author{
I. Llorente and E. Montesinos, Institute of Food and Agricultural Technology-CeRTA, University of Girona, Av.
} Lluís Santaló s/n, 17071 Girona, Spain

\begin{abstract}
Llorente, I., and Montesinos, E. 2004. Development and field evaluation of a model to estimate the maturity of pseudothecia of Pleospora allii on pear. Plant Dis. 88:215-219.

The effect of temperature and of two levels of relative humidity (RH) on maturity of pseudothecia of Pleospora allii (teleomorph of Stemphylium vesicarium) was studied under controlled environmental conditions at temperatures of $5,10,15,20,25$, and $30^{\circ} \mathrm{C}$ and high $(\geq 98 \%)$ and low $(\approx 60 \%)$ RH. Pseudothecia developed only at high $\mathrm{RH}$, and the optimum temperature was between 10 and $15^{\circ} \mathrm{C}$. A regression model of the form $\ln (1 / 1-y)=0.12550+0.005048 x$, which related the proportion of mature pseudothecia $(y)$ to cumulative degree-days $(x)$, was developed with data from two controlled environment experiments. Maturation of pseudothecia also was studied in leaf debris in pear orchards affected by brown spot of pear in seven field trials during 4 years. Asci with mature ascospores were observed in leaf debris from mid-January to May. A significant linear relationship was observed between the predicted values according to the monomolecular model and observed values of the percentage of mature pseudothecia in the field trials $\left(r^{2}=0.91\right.$, intercept $=8.718$, and slope $\left.=0.903\right)$. This model can be used to predict the onset of ascospore discharge and for determining the initiation of fungicide applications to control the primary inoculum and prevent primary infections.
\end{abstract}

Brown spot of pear (Pyrus communis L.), caused by the fungus Stemphylium vesicarium (Wallr.) E. Simmons, can produce high economic losses if weather conditions are favorable for infections. Several peargrowing areas are affected by the disease in Spain, Italy, France, Holland, and Portugal $(1,5,12,21,28)$. The most susceptible pear cultivars to brown spot are Abate Fetel, Passe Crassane, Alexandrine, and Conference $(1,3,17)$. Disease control is achieved with fungicides applied at a fixed spray schedule every 7 or 15 days, starting after petal fall and ending a few weeks before harvest $(11,13,16,19,21,28)$. A forecasting system for brown spot (BSPcast) has been developed, evaluated, and validated in Spain and Italy to reduce fungicide use in disease management programs $(13,18)$. The number of fungicide applications was reduced by 20 to $70 \%$ by using BSPcast, while still maintaining the same level of disease control as in the fixed-spray schedule $(11,13)$.

Corresponding author: I. Llorente

E-mail: isidre.llorente@udg.es

This research was supported in part by grants from Instituto Nacional de Investigaciones Agrarias (SC99-055) and Subdirección General de Cooperación Internacional (HI96-120B) of Spain, and Comissió Interdepartamental de Recerca i Tecnologia of the Generalitat de Catalunya.

Accepted for publication 21 October 2003.

Publication no. D-2003-1208-02R

(C) 2004 The American Phytopathological Society
S. vesicarium overwinters on pear in fallen infected leaves or fruit as pseudothecia of its teleomorph Pleospora allii (Rabenh.) Ces. \& De Not. Development of the ascigerous state begins after leaf fall, continues during late autumn and winter, and resumes the following spring when the pseudothecia mature and ascospores are released $(3,16)$. Management of the primary inoculum may be critical for control of brown spot of pear because a reduction in numbers of ascospores or a delay in their maturity may considerably decrease disease intensity at the end of the epidemics (29). In fungal pathogens with epidemiology similar to that of $S$. vesicarium, such as Venturia inaequalis on apple, a reduction in the amount of overwintering inoculum produced a decrease in the subsequent levels of disease incidence and severity $(7,25)$.

Knowledge of the effect of factors affecting pseudothecial development of $P$. allii on pear also is needed to refine control programs designed to decrease the primary inoculum and to improve the accuracy of the BSPcast forecasting system. Studies of pseudothecial development in $P$. allii have been carried out on garlic (22) but not on pear. The objectives of the present research were to (i) study the effect of temperature and two levels of relative humidity $(\mathrm{RH})$ on pseudothecial development under controlled environmental conditions, (ii) develop a predictive model to estimate the percentage of mature pseudothecia, and (iii) evaluate the model under field conditions in pear orchards.
MATERIALS AND METHODS

Production of pseudothecia under controlled-environment conditions. A strain of $S$. vesicarium (EPS26) isolated from an infected pear fruit was used for production of pseudothecia of $P$. allii. Cultures of $S$. vesicarium were grown on V8 agar, composed of 1 liter of distilled water, $100 \mathrm{~g}$ of V8 juice, $3 \mathrm{~g}$ of $\mathrm{CaCO}_{3}$, and $20 \mathrm{~g}$ of agar. The $\mathrm{pH}$ was adjusted to 7. Fungal cultures were incubated at $20^{\circ} \mathrm{C}$ with a daily photoperiod of $16 \mathrm{~h}$ of fluorescent light and $8 \mathrm{~h}$ of darkness. When petri dishes were completely covered by $S$. vesicarium mycelium, normally 20 to 30 days after the inoculation, pseudothecia of $P$. allii were observed under the microscope.

Assessment of the stage of development of the pseudothecia. A previously reported scale based on fungi related to $P$. allii $(10,22,27)$ was used to determine the developmental stages of individual pseudothecia. Values were assigned to each pseudothecium as follows: 1, pseudothecium primordia; 2 , pseudoparaphyses filling the lumen of the pseuodothecium; 3 , initiation of asci differentiation; 4, asci with undifferentiated ascospores; 5, asci with immature ascospores and asci with mature ascospores; 6, all the asci with mature ascospores; 7, pseudothecia with some asci empty or broken releasing the ascospores; and 8, pseudothecia with empty or no asci. A pseudothecial maturation index was calculated according to the following equation:

$$
\mathrm{MI}=\frac{\sum_{i=1}^{8}\left(i \times n_{i}\right)}{N}
$$

where MI is the maturity index, $i$ is the developmental stage ( 1 to 8 ) of the pseudothecia, $n_{i}$ is the number of pseudothecia in developmental stage $i$, and $N$ is the total number of pseudothecia surveyed. Under controlled environmental conditions, the stages observed ranged from 2 to 7 ; whereas, in the field, the stages ranged from 2 to 8 .

Effects of temperature and two levels of RH on maturity of pseudothecia under controlled environmental conditions. Cultures containing pseudothecia of $P$. allii in stage 2 were used. Aerial mycelium and conidia of $S$. vesicarium, grown on petri dishes, were scraped from the surface of the fungal colony with a cotton swab and sterile water. Agar pieces $\left(0.5 \mathrm{~cm}^{2}\right)$ 
containing 10 to 15 pseudothecia were cut from the dishes. Two pieces were placed on a fiberglass mesh $(10$ by $10 \mathrm{~cm})$ which then was pasted using glue to the inner side of the cover of a square petri dish (15 by $15 \mathrm{~cm}$ ). The surface of each agar piece was facing the bottom of the petri dish and raised above it to avoid contact with the bottom base. Sterile filter paper was placed in the bottom of the dish and moistened with sterile water to maintain high $\mathrm{RH}(\geq 98 \%)$. Saturated saline solution $\left(\mathrm{MgNO}_{3} \cdot 6 \mathrm{H}_{2} \mathrm{O}\right)$ was used to maintain low RH $(\approx 60 \%)$. All possible combinations of temperature $\left(5,10,15,20,25\right.$, or $\left.30^{\circ} \mathrm{C}\right)$ and $\mathrm{RH}$ (98 or $60 \%$ ) were tested under darkness in controlled environment chambers (models 350 and $350 \mathrm{H}$; Sanyo, Gunma, Japan). After the start of the experiment, three petri dishes per treatment combination were sampled every 6 to 9 days. Ten pseudothecia were removed from the agar pieces and were transferred with a fine forceps to a glass slide containing a small drop of distilled water. The pseudothecial wall was broken by applying gentle pressure to the cover glass in order to spread the asci in a thin layer and was observed with a light microscope at $\times 100$ to $\times 200$. The maturity index was calculated according to the equation described above. A total of 39 independent petri dishes, sealed with Parafilm, per each treatment combination were prepared. The entire experiment was conducted twice. Data

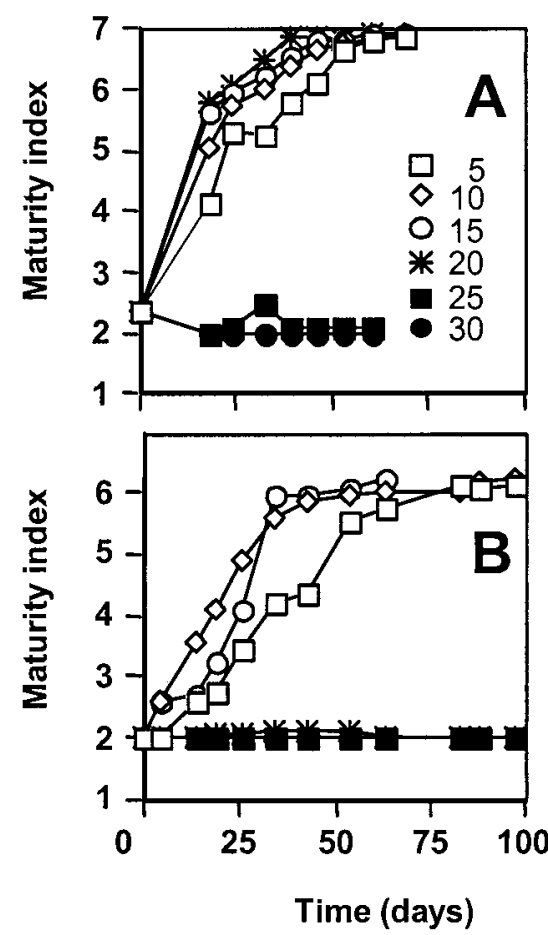

Fig. 1. Time course of the maturity index of Pleospora allii pseudothecia at temperatures of $5,10,15,20,25$, and $30^{\circ} \mathrm{C}$ under controlled environment conditions at high relative humidity $(\geq 98 \%)$. Data show the mean of three replicates for each temperature and time. A, Experiment I and B, experiment II. from the two experiments were compared using an analysis of covariance with cumulative degree days (CDD) as a covariate. Data were analyzed using the Proc GLM (SAS System v. 8.00; SAS Institute, Cary, NC).

Model development. A model was developed to estimate the percentage of mature pseudothecia in relation to CDD using pooled data from the two controlled environment experiments. Pseudothecia were considered mature when the stage of development was $\geq 6$. The percentage of pseudothecia at stage $\geq 6$ was calculated for each time, temperature, and replicate. Degree days (DD) were calculated as the product between temperature $\left({ }^{\circ} \mathrm{C}\right)$ and the time (days) elapsed from the first observation of mature pseudothecia. Linear regression was used to determine the relationship between the percentage of mature pseudothecia and CDD. The percentage of mature pseudothecia was standardized by dividing by 100 and transformed according to the monomolecular, logistic, Gompertz, exponential, and probit transformations to obtain linear relationships. The models were evaluated for fit based on $r^{2}, r^{2}$ obtained from the relationship between predicted back-transformed values and observed values, mean square error (MSE), MSE*, and residual analysis (2). The upper and lower bounds of the $95 \%$ confidence interval also were calculated.

Model evaluation on field trials. Seven trials were performed under field conditions from October to May 1996, 1997, 1998, and 1999 at four different locations in Girona, Spain. Air temperature and RH were monitored with CR10 or CR10X dataloggers (Campbell Scientific Ltd., Leicester, UK) connected to combined temperature-RH (model MP100 or HMP35AC) or temperature (model 107) sensors. Sensors were placed in trees at 1.5 to $1.8 \mathrm{~m}$ above the soil surface and in the middle of orchard plots. Temperature and RH were measured every $10 \mathrm{~min}$, and means were recorded hourly.

Pear leaves (Pyrus communis L., cv. Conference) with brown spot lesions caused by $S$. vesicarium were collected from trees in different orchards at early leaf fall at the end of October in 1996 and 1998. These trees had not received fungicide sprays during the previous 4 weeks. Fifteen fiberglass nets $(25$ by $25 \mathrm{~cm})$, each containing 10 leaves, were placed on the orchard floor in each orchard. No fungicides were sprayed in these plots during the experiment. One fiberglass net containing infected leaves was removed from each orchard every 7 to 15 days from January to May and transported to the laboratory. Pseudothecia from leaves were selected arbitrarily at $\times 30$ and transferred using fine forceps to a distilled water drop placed on a glass slide. Pseudothecia were crushed with the aid of a coverslip and mean stage of pseudothecial development was deter- mined as previously described at $\times 100$ or $\times 200$ for each sampling time and trial for at least 30 pseudothecia selected arbitrarily from all leaves. In some cases, only 15 to 20 pseudothecia were found.

The model was evaluated using data from the seven field trials. First, the percentage of pseudothecia at stage $\geq 6$ was estimated with the model obtained from controlled environment experiments using CDD data corresponding to each sampling time and field trial. DD were calculated by the single triangulation method using a base threshold of $0^{\circ} \mathrm{C}$. For calculation of CDD, DD were accumulated from the day when the first mature pseudothecium was observed.

Linear regression analyses were performed using Proc GLM to determine the relationship between the predicted backtransformed values from the model and the observed percentage of mature pseudothecia for the pooled data of the seven field trials. Evaluation of the model was based on how close the coefficient of determination $\left(r^{2}\right)$ and slope parameter were to 1 , and how close the intercept parameter estimate was to 0 .

\section{RESULTS}

Effect of temperature and two levels of RH on maturity of pseudothecia. No mature pseudothecia were observed when RH was $60 \%$ at any of the incubation temperatures studied in the two experiments performed under controlled environmental conditions. Also, no mature pseudothecia were observed under incubation at $\geq 98 \%$ $\mathrm{RH}$ at 25 or $30^{\circ} \mathrm{C}$ in experiment I and 20 or $25^{\circ} \mathrm{C}$ in experiment II (Fig. 1). In experiment I, after incubation in high $\mathrm{RH}$ at $5,10,15$, or $20^{\circ} \mathrm{C}$, pseudothecia reached maturity (stage 6) after 30 to 50 days and reached stage 7 after 50 to 60 days (Fig. 1A). In experiment II, results were similar to experiment I for temperatures of 5, 10, and $15^{\circ} \mathrm{C}$ but not for $20^{\circ} \mathrm{C}$. However, in experiment II, pseudothecia reached stage 6 after 40 days at 10 and $15^{\circ} \mathrm{C}$ and after 70 to 80 days at $5^{\circ} \mathrm{C}$ (Fig. 1B), and did not reach stage 7 after 100 days of incubation at high RH. Also, a significant number of aborted pseudothecia were observed at $20^{\circ} \mathrm{C}$.

The time course of pseudothecial maturation could be divided into two phases (Fig. 1). In the first phase (from stage 2 to 5 ), the progression was relatively linear and required about 190 CDD. In the second phase (above stage 5), pseudothecia matured slowly and required an additional $400 \mathrm{CDD}$. Therefore, temperature requirements as an average CDD per stage were lower for stages below 6 than for stages above 6 .

Development of a model to estimate the proportion of mature pseudothecia from CDD. Plots of the proportion of mature pseudothecia (stage $\geq 6$ ) against CDD were very similar for the two experi- 
ments (Fig. 2). No significant differences $(P=0.3635)$ between experiments were observed when comparing data of mature pseudothecia with an analysis of covariance using CDD as covariate. Consequently, a model was developed using pooled data from both experiments. The best relationship between pseudothecial maturation and CDD was obtained when the proportion of mature pseudothecia was linearized using the monomolecular or the Gompertz functions. The monomolecular function was chosen because it is much simpler than Gompertz. Therefore, the monomolecular function corresponding to the following equation was selected: $\ln (1 / 1$ $-y)=b_{0}+b_{1} C D D$, where $y$ is the proportion of mature pseudothecia, $b_{0}$ is the intercept parameter, $b_{1}$ is the slope parameter, and $C D D$ is the cumulative

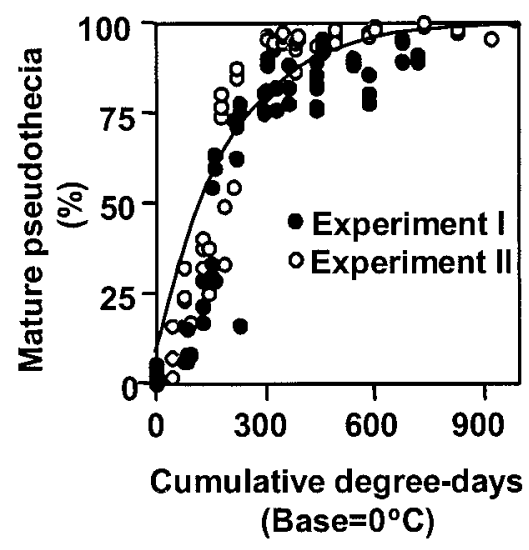

Fig. 2. Relationship between maturation of Pleospora allii pseudothecia and degree-day accumulation under controlled environment conditions at high relative humidity $(\geq 98 \%)$ for two experiments. The solid line represents data adjusted to the monomolecular model and is presented in original units using pooled data of two experiments. Calculation of cumulated degree days began when the first mature pseudothecia were observed (stage $\geq 6$ ) and was performed using $0^{\circ} \mathrm{C}$ as the base temperature.

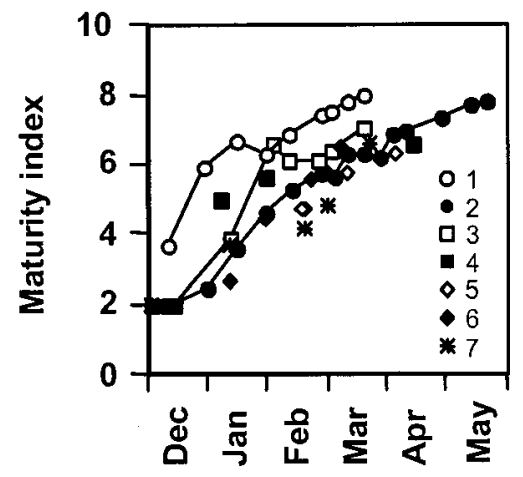

Date

Fig. 3. Time course of the maturity index of Pleospora allii pseudothecia in infected leaf debris in the seven field trials performed during 1996 to 1999 in several pear orchards in Girona, Spain. degree days. The parameter estimates were $b_{0}=0.12550$ and $b_{1}=0.005048\left(r^{2}=0.70\right.$ and $P<0.0001, r^{2} *=0.89$ and $P>$ $0.0001)$.

Back-transformed values $(y)$ were obtained by solving the equation for $y$, where $z=\ln (1 / 1-y)$. The curve predicted by the model using back-transformed values $(y=$ $\left.1-\left[1 / e^{z}\right]\right)$ depicted a saturation relationship between the percentage of mature pseudothecia and CDD (Fig. 2). Pseudothecial maturation occurs in an accelerated phase from $y_{0}$ to about $90 \%$ maturity $(\leq 432 \mathrm{CDD})$, and a decelerated phase from 90 to $100 \%$ (>432 CDD). Approximately $98 \%$ of pseudothecia of $P$. allii were mature after $750 \mathrm{CDD}$.

Model evaluation in field trials. Maturation of pseudothecia progressed from December (stage 2) to May (stage 8) (Fig. 3 ) in field trials. The beginning of developmental stage 6 was observed on 2 February, 26 February, 12 December, 7 January, 29 January, 8 February, and 18 February in trials 1 through 7, respectively. Dates when more than $90 \%$ of pseudothecia had reached stage 6 were 19 March, 10 April, 3 March, 13 April, 13 April, 8 March, and 22 March in trials 1 through 7, respectively.

The relationship between the proportion of mature pseudothecia observed in field trials and CDD is presented in Figure 4, along with the predicted line from the model developed from controlled environment experiments. Pseudothecial maturity observed in field trials was closely related to CDD with a base temperature of $0^{\circ} \mathrm{C}$. Of 33 data points, 31 fell within the $95 \%$ confidence interval.

The relationship between mature pseudothecia predicted by the model and the observed data from the seven trials was analyzed by linear regression (Fig. 5). The model was a good predictor, as judged by the regression statistics $\left(r^{2}=\right.$ $0.91, P<0.0001)$ and slope parameter estimate (0.90). However, the model showed a slight tendency to underestimate at values lower than $25 \%$ mature pseudothecia and overestimate in the range of 25 to $75 \%$.

\section{DISCUSSION}

$\mathrm{RH}$ and temperature are important factors influencing the development of pseudothecia of pear isolates of $P$. allii. RH seems an important limiting factor governing maturation, because pseudothecia only mature when $\mathrm{RH}$ is close to the saturation point. These results agree with observations that high humidity is necessary for pseudothecial development in $P$. allii on garlic (22) and other related fungi, such as Venturia inaequalis on apple $(8-10,20)$ and Didymella rabiei on chickpea (27).

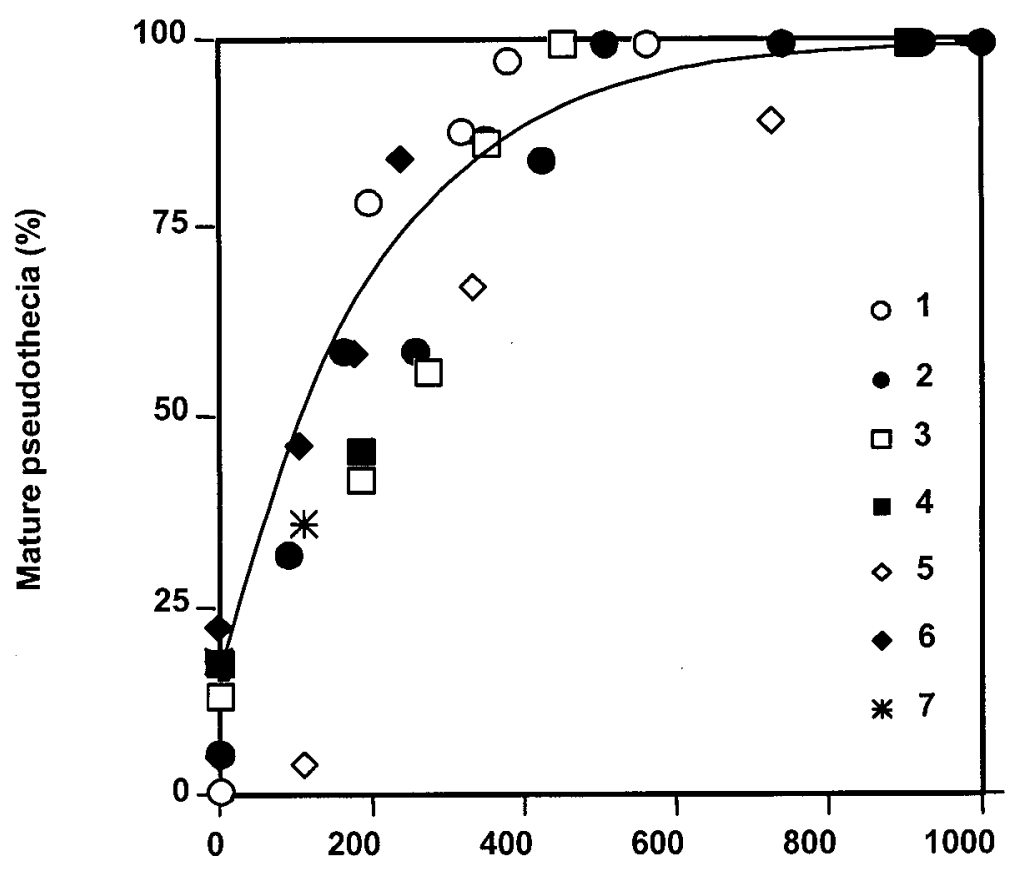

\section{Cumulative degree-days}

\section{$\left(\right.$ Base $\left.=0^{\circ} \mathrm{C}\right)$}

Fig. 4. Percentage of mature pseudothecia predicted by the cumulated degree days compared with field observations. Degree days were cumulated from the first observation of mature pseudothecia and were calculated using $0^{\circ} \mathrm{C}$ as the base temperature. The solid line represents data obtained from controlled environment conditions adjusted to the monomolecular model. The data points correspond to the seven field trials performed during 1996 to 1999 in several pear orchards in Girona, Spain. 
Under high RH conditions, development of pseudothecia of $P$. allii is dependent on temperature. The optimal temperature for maturation of pseudothecia of pear isolates is between 10 and $15^{\circ} \mathrm{C}$, and rates of maturation decreased at $5^{\circ} \mathrm{C}$; whereas no maturation was observed above $25^{\circ} \mathrm{C}$. However, our results differ from an optimal temperature between 5 and $10^{\circ} \mathrm{C}$ reported for $P$. allii on garlic debris infected with $S$. vesicarium (22). Nevertheless, the period of 40 days required for maturation of ascospores at $15^{\circ} \mathrm{C}$ and the failure of ascospores to mature at $25^{\circ} \mathrm{C}$ in pear isolates of $P$. allii agreed with the data reported for isolates from alfalfa in the United States (4).

In the present study, the relationship between the percentage of mature pseudothecia and CDD was described by a monomolecular mathematical function. According to this model, fewer CDD were required for maturation of $P$. allii pseudothecia than for other fungi affecting apple and pear. Approximately $98 \%$ of pseudothecia of $P$. allii were fully mature after only 750 CDD, whereas $V$. inaequalis $(6,15)$ and $V$. pirina $(23,24)$ require $1,000 \mathrm{CDD}$.

Use of forecasting models to estimate the proportion of mature pseudothecia in the field requires that the computation of CDD be initiated on an appropriate date (biofix). In some fungi, the biofix is based on the phenological stage of the host plant, such as silver tip or green tip in apple $(14,15)$, or the date of $50 \%$ petal fall $(26)$. In other cases, fixed calendar dates are used (10). However, the phenological stage may differ among regions (15) and calendar dates do not take into account climatic differences between regions. This problem can be avoided using the date of detection of the first mature pseudothecia (e.g., stage $\geq 6$ ) by examining field samples periodically, as was used in models for forecasting maturation of $V$. inaequalis (6) and $V$. pirina (23). Alternatively, as discussed
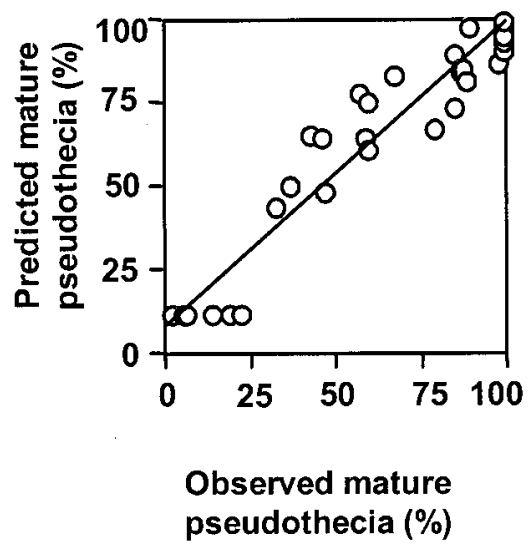

Fig. 5. Predicted percentage of mature Pleospora allii pseudothecia plotted against observed data in seven field trials performed during years 1996 through 1999. The solid line indicates the fit between predicted and observed data $\left(y=0.903 x+8.718, r^{2}=0.91\right)$. The regression was significant at $P<0.0001$. above, a biofix based on the phenological stage of pear trees could be used, thereby eliminating the need for early spring assessments of pseudothecial maturity. However, the validity of this approach should be tested experimentally.

The pseudothecial maturity model derived from the present work under controlled environmental conditions was evaluated in 1996, 1997, 1998, and 1999 at four diverse locations in seven trials. The model was validated because most predicted values (31 of 33) fell within the 95\% confidence interval, and linear regression of predicted on observed proportion of mature pseudothecia resulted in $r^{2}$ and slope values close to 1 . However, the model suffers from a slight overestimation of the predictions. This can be explained because the model is based on controlled environment conditions of constant temperature and RH; whereas, in fruit or leaf debris on the orchard floor, the pseudothecia are subjected to discontinuous temperature and $\mathrm{RH}$ conditions or moisture availability. Thus, in the field, pseudothecia develop under less favorable conditions than in controlled environment experiments.

Dates of observation of the first mature pseudothecia in pear orchards differed as much as 6 weeks depending on orchard conditions (from 12 December to 26 February). However, once pseudothecia began to mature, development continued at a similar rate in all locations in response to DD accumulation. Thus, the model can be used for determining when pseudothecia and ascospores mature. Knowing when pseudothecia and ascospores mature is of fundamental importance to predict the onset of ascospore discharge and for determining the initiation of fungicide applications to control the primary inoculum and prevent primary infections. In addition, it can be used to establish the date to begin running the BSPcast system for scheduling fungicide applications to control of secondary infections $(13,18)$. Therefore, the algorithm for predicting the maturation of pseudothecia in relation to CDD will be incorporated as a component of BSPcast. However, to increase the accuracy of predictions, additional studies using spore traps should be performed because the release of ascospores of $P$. allii is dependent on rain or heavy dew (22, unpublished results). Also, additional weather variables (e.g., RH, wetness, or rain) should be incorporated in the pseudothecial maturity model, and the model should be evaluated and validated in other geographical locations.

\section{ACKNOWLEDGMENTS}

We thank X. Solà, M. Calderon, C. Isart, and J. Pereda for their helpful assistance in field and laboratory work.

\section{LITERATURE CITED}

1. Blancard, D., Allard, E., and Brest, P. 1989. La Stemphyliose du poirier ou "macules brunes."
Phytoma 406:37-38.

2. Campbell, C. L., and Madden, L. V. 1990. Introduction to Plant Disease Epidemiology. John Wiley and Sons, New York.

3. Cavanni, P., and Ponti I. 1994. Maculatura bruna del pero: una micopatia sempre d'attualità. Riv. Fruticultura 12:37-42.

4. Chairsrisook, C., Suteville, D. L., and Skinner, D. Z. 1995. Five Stemphylium spp. pathogenic to alfalfa: occurrence in the United States and time requirements for ascospore production. Plant Dis. 79:369-372.

5. Cugier, J. P., and Humbert, W. 1991 Stemphyliose du poirier. Etude de la biologie du parasite et recherches des fongicides actifs. Phytoma 431:47-50.

6. Gadoury, D. M., and MacHardy, W. E. 1982. A model to estimate the maturity of ascospores of Venturia inaequalis. Phytopathology 72:901-904.

7. Gadoury, D. M., and MacHardy, W. E. 1986. Forecasting ascospore dose of Venturia inaequalis in commercial apple orchards. Phytopathology 76:112-118.

8. Gadoury, D. M., MacHardy, W. E., and Hu, C. 1984. Effects of temperature during ascus formation and frequency of ascospore discharge on pseudothecial development of Venturia inaequalis. Plant Dis. 68:223-225.

9. James, J. R., and Sutton, T. B. 1982. Environmental factors influencing pseudothecial development and ascospore maturation of Venturia inaequalis. Phytopathology 72:10731080.

10. James, J. R., and Sutton, T. B. 1982. A model for predicting ascospore maturation of Venturia inaequalis. Phytopathology 72:10811085 .

11. Llorente, I. 1997. Development of an infection forecasting model for Stemphylium vesicarium. Evaluation, validation and implementation on experimental plots in commercial pear orchards. Ph.D. thesis. University of Girona, Girona, Spain.

12. Llorente, I., and Montesinos, E. 2002. Effect of relative humidity and interrupted wetness periods on brown spot severity of pear caused by Stemphylium vesicarium. Phytopathology 92:99-104.

13. Llorente, I., Vilardell, P., Bugiani, R., Gherardi, I., and Montesinos, E. 2000. Evaluation of BSPcast disease warning system in reduced fungicide use programs for management of brown spot of pear. Plant Dis. 84:631-637.

14. MacHardy, W. E., 1996. Apple Scab: Biology, Epidemiology, and Management. American Phytopathological Society Press, St. Paul, MN.

15. MacHardy, W. E., and Gadoury, D. M. 1985. Forecasting the seasonal maturation of ascospores of Venturia inaequalis. Phytopathology 75:381-385.

16. Montesinos, E., Llorente, I., Moragrega, C., Bonaterra, A., Cervantes, J., and Vilardell, P. 1996. Desarrollo y evaluación a escala productiva de un sistema de control racional de la estemfiliosis (Stemphylium vesicarium) del peral. Fruticultura Profesional 78:96-104.

17. Montesinos, E., Moragrega, C., Llorente, I., and Vilardell, P. 1995. Susceptibility of selected European pear cultivars to infection by Stemphylium vesicarium and influence of leaf and fruit age. Plant Dis. 79:471-473.

18. Montesinos, E., Moragrega, C., Llorente, I., Vilardell, P., Bonaterra, A., Ponti, I., Bugiani, R., Cavani, P., and Brunelli, A. 1995. Development and evaluation of an infection model for Stemphylium vesicarium on pear based on temperature and wetness duration. Phytopathology 85:586-592.

19. Montesinos, E., and Vilardell, P. 1992. Evaluation of FAST as a forecasting system for scheduling fungicide sprays for control of 
Stemphylium vesicarium on pear. Plant Dis. 76:1221-1226.

20. O'Leary, A. L., and Sutton, T. B. 1986. The influence of temperature and moisture on the quantitative production of pseudothecia of Venturia inaequalis. Phytopathology 76:199-204.

21. Ponti, I., Cavanni, P., and Brunelli, A. 1982. "Maculatura bruna" delle pere: eziologia e difesa. Inf. Fitopatol. 3:35-40

22. Prados-Ligero, A. M., González-Andújar, J. L., Melero-Vara, J. M., and Basallote-Ureba, M. J. 1998. Development of Pleospora allii on garlic debris infected by Stemphylium vesicarium. Eur. J. Plant Pathol. 194:861-870.
23. Spotts, R. A., and Cervantes, L. A. 1994. Factors affecting maturation and release of ascospores of Venturia pirina in Oregon. Phytopathology 84:260-264.

24. Spotts, R. A., Cervantes, L. A., and Niederholzer, F. J. A. 2000. Pear scab: Components of potential ascospore dose and validation of an ascospore maturity model. Plant Dis. 84:681683.

25. Sutton, D. K., MacHardy, W. E., and Lord, W. G. 2000. Effects of shredding or treating apple leaf litter with urea on ascospore dose of Venturia inaequalis and disease buildup. Plant. Dis. 84:1319-1326.
26. Sutton, T. B., James, J. R., and Nardacci, J. F. 1981. Evaluation of a New York ascospore maturity model for Venturia inaequalis in North Carolina. Phytopathology 71:1030-1032.

27. Trapero-Casas, A., and Kaiser, W. J. 1992. Development of Didymella rabiei, the teleomorph of Ascochyta rabiei, on chickpea straw. Phytopathology 82:1261-1266.

28. Vilardell, P. 1988. Stemphylium vesicarium en plantaciones de peral. Fruticultura Profesional 18:51-55

29. Zadoks, J. C., and Schein, R. D. 1979. Epidemiology and Plant Disease Management. Oxford University Press, Oxford. 